\title{
Morphometry of Pedicle and Vertebral Body in a Mexican Population by $\mathrm{CT}$ and Fluroscopy
}

\author{
Morfometría del Cuerpo Vertebral y Pedículo en una \\ Población Mexicana Mediante TC y Fluoroscopía
}

Edgar Urrutia Vega; Rodrigo E. Elizondo Omaña; Oscar De la Garza Castro \& Santos Guzmán López

URRUTIA, V. E.; ELIOZONDO, O. R. E.; DE LA GARZA, C. O. \& GUZMÁN, L. S. Morphometry of pedicle and vertebral body in a Mexican population by CT and Fluroscopy. Int. J. Morphol., 27(4):1299-1303, 2009.

SUMMARY: It is necessary to have precise anatomical knowledge of lumbar pedicles for the safe placement of screws. There are not reports about the morphometry of lumbar pedicles in a Mexican population exist. A descriptive, observational and cross-sectional study was done in 60 cadavers from the dissection lab of the Human Anatomy Department of the Medicine School. The aim of the study was to quantify the morphometric characteristics of the pedicles of the lumbar spine in a Mexican population. A total of 60 cadavers were evaluated by fluoroscopy and CT from L1 to L5, in the age range of 40 to 78 years. Each vertebral pedicle was measured in the axial, sagittal and coronal planes. The measurements included the minimum pedicle width, the pedicle angle, the distance to anterior cortex, and anteroposterior and interpedicular spinal canal diameters. CT evaluation showed a progressive and gradual increase in the width of the pedicles from L1 $(7.81 \pm 1.30 \mathrm{~mm})$ to L5 $(14.36 \pm 14.36 \mathrm{~mm})$. A progressive and gradual decrease of pedicle length from L1 (20.92 $\pm 2.62 \mathrm{~mm})$ to L5 $(17.23 \pm 1.35 \mathrm{~mm})$. When fluoroscopy was used there was the same relationship, but the values were higher than those obtained by CT. The values for widths and lengths are slightly higher in males than in females, but do not reveal any significant difference $(\mathrm{p}<0.05)$. The data in this study indicates that pedicle screws $(5.5-6.5 \mathrm{~mm})$ may be used in the lumbar region.

KEY WORDS: Pedicles; Vertebral body; Morphometry; Intrapedicular screws; Lumbar fusion surgery.

\section{INTRODUCTION}

The number of patients with degenerative diseases of the lumbar spine is increasing, which seems to be a natural consequence of aging due to the increase in life expectancy. It is estimated that between $70-90 \%$ of the general population suffer from low back pain and that approximately $4 \%$ require surgery at some time (Gelalis \& Kang, 1998).

One treatment option for these degenerative disorders is lumbar fusion surgery which can be performed with an open or minimally invasive technique (Humphreys et al., 2001; Errico et al., 2004). Currently minimally invasive surgery is preferred because it offers advantages in postoperative recovery (Khoo et al., 2002).

In order to perform a lumbar fusion by minimally invasive surgery technique is necesary to have precise anatomical knowledge of lumbar pedicles. The CT scan evaluation represents the most frecuent procedure before the surgery, and fluroscopy is used during the surgical procedure to guide surgeon in screw fixation.

Lower lumbar pedicle size differs between ethnic race. Until now, there is reports regarding the morphology of pedicles in Americans, Indian, Koreans, Greek, Malaysian, and Japanese populations (Olsewski et al., 1990; Mitra et al., 2002; Kim et al., 1994; Christodolou et al., 2005; Liau et al., 2006; Nojiri et al., 2005). Knowledge of pedicle dimensions and surface landmarks is crucial for the safe placement of screws, but there is not quantitative data concerning the lower lumbar pedicle using CT scan and fluroscopy in mexican population exist. The aim of this study was to evaluate lumbar pedicle dimensions in a mexican population by computed axial tomography and fluroscopy. 


\section{MATERIAL AND METHOD}

A descriptive, observational and cross-sectional study was done in 60 cadavers from the dissection lab of the Human Anatomy Department of the Medicine School with an age range at the time of death between 40 and 78 years. The cadavers showing obvious deformity in the spine or a fractured spine were excluded from this study.
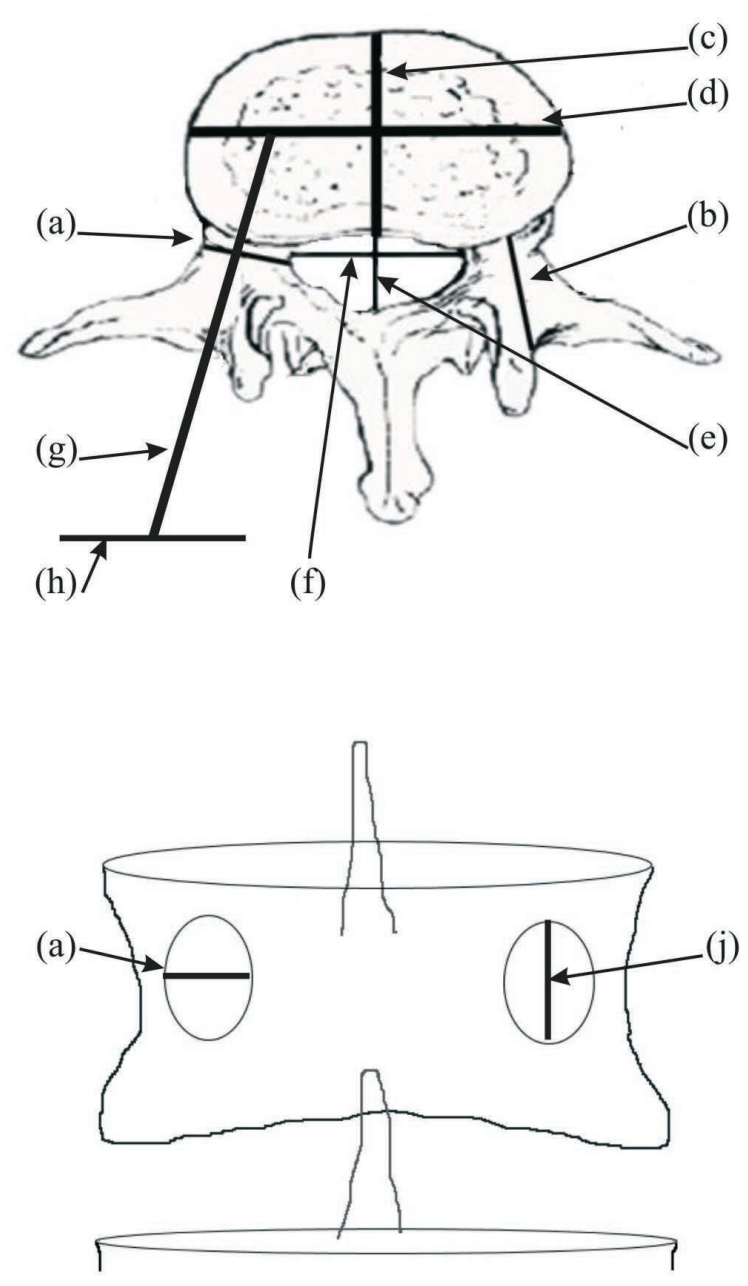

Computerized tomography (CT) scans and fluoroscopy of the lumbar region of the cadavers was done to perform morphometry of the vertebras. For both imaging techniques the following measures were taken into consideration: pedicle width and length and the anteroposterior diameter of the vertebral body. Also, using CT the following were obtained: transverse diameter of the vertebral body, anteroposterior and transverse diameter of the spinal canal and vector 1. Using fluoroscopy we also obtained: pedicle height and vertebral body height (Fig. 1).
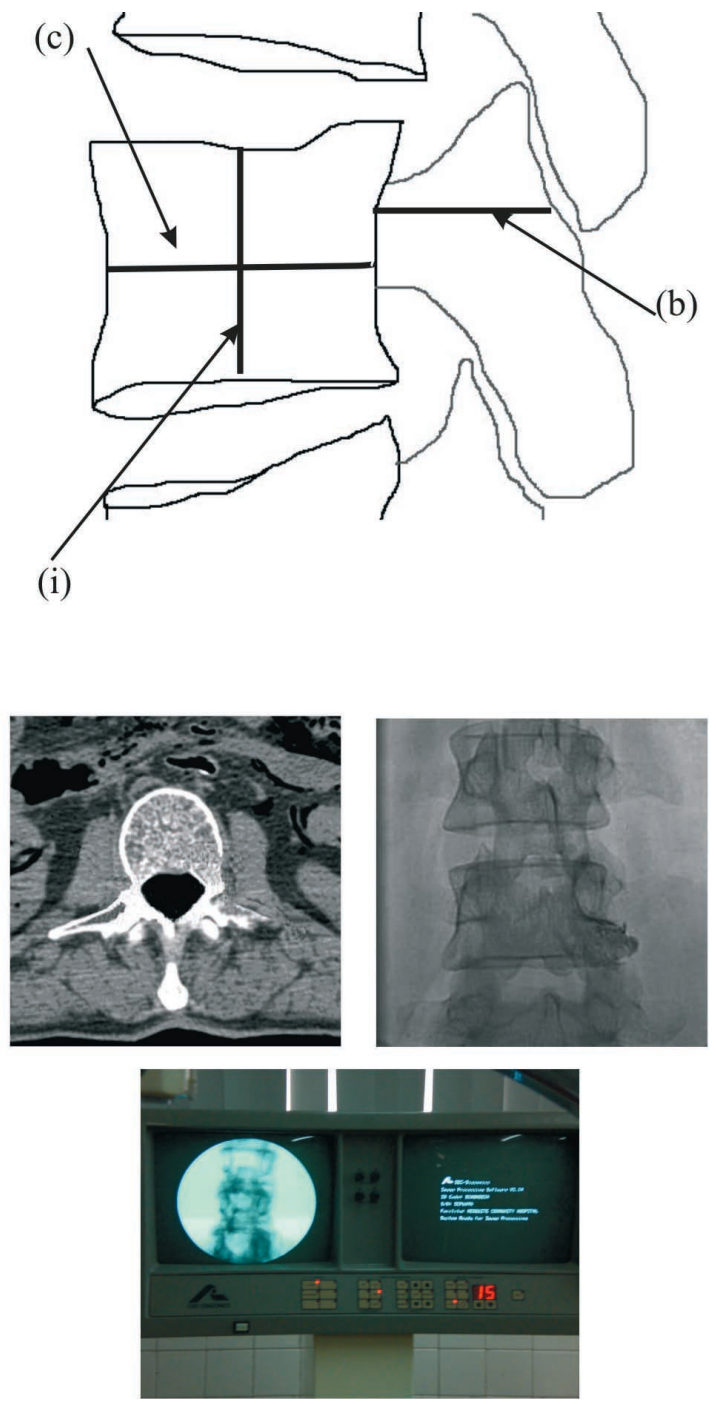

Fig. 1. Diagram showing the measurements made by CT and fluoroscopy. (a) Pedicular width. Transverse diameter of the pedicle measured from both external cortexes of the pedicle. (b) Pedicular length. Measured from the posterior border of the vertebral body at the level of the upper border of the pedicle to the posterior border of the upper articular facet. (c) anteroposterior diameter of the vertebral body. Length measured on the midline of the vertebral body from the external cortex of the anterior border to the external cortex of the posterior border. (d) Transverse diameter of the vertebral body. Measured from the external cortex of the right border to the external cortex of the left border. (e) Anteroposterior diameter of the spinal canal. The length that exists between the external cortex of the posterior border of the vertebral body to the external cortex of the union of the vertebral lamina. (f) Transverse diameter of the spinal canal. The distance that exists between the external cortex of the medial border of both pedicles. $(\mathrm{g})$ Vector 1 . The distance from the skin of a line that intersects with the transverse diameter of the vertebral body to the transpedicular line. (h) Skin. Graphic representation of the skin surface of the lumbar region. (i) Vertebral body height. (j) Pedicle height. 
A multi-slice CT scanner was used to analize the lumbar vertebrae. Slice thickness was 3 or $4,5 \mathrm{~mm}$ with a table incrementation of $4.5 \mathrm{~mm}$. The measures obtained by CT were made with CD-viewer 2.0 software from GE Medical Systems. The measures taken with the DEC DIASONIC fluoroscope with a $\mathrm{C}$ arc were done using the images on the monitor with a vernier caliper with a resolution of $0.01 \mathrm{~mm}$. The distance between object and image intensifier was $40 \mathrm{~cm}$. The data are given as the mean, standard deviation and other measures of central tendency for each vertebral level were obtained bilaterally (in both pedicles). For comparison of the averages for both imaging techniques a student's t test was used with a stastistical significance of $\mathrm{p}<0.05$.

\section{RESULTS}

Sixty vertebrae were analized by CT and fluroscopy. Three measurements were obtained by CT and fluroscopy: pedicle width and length and anteroposterior diameter of the verterbal body. Aditionally, three more measurements by CT (transverse diameter of vertebral body, anteroposterior and transverse diameter of spinal canal and vector 1) and two more by fluroscopy (pedicle height and vertebral body height) were obtained.

CT scan evaluations. Pedicles: A progressive and gradual increase in the width of the pedicles from L1 to L5 was observed (Table I). In both males and females, the widest pedicle width was located at L5 and the narrowest was located at L1 (Table I). A progressive and gradual decrease of pedicle length from L1 to L5 was observed (Table I).

Body: The anteroposterior and transverse diameter of the vertebral body increases slightly and a significant increase was observed only in L5 (Table I).

Spinal Canal: The shape of the spinal canal at the lumbar level is romboidal with a greater transverse diameter. The transverse diameter increases slightly and progressively from L1 to L5 (Table I).

Vector 1: The length of vector 1 increases when descending in the lumbar spine (Table I).

Fluoroscopy evaluations. Pedicles: A progressive and gradual increase in the width of the pedicles from L1 to L5 was observed when the anteroposterior projections of the pedicles were measured (Table II). When the length of the pedicles were measured in lateral projections a decrease as lower segments were analyzed was found (Table II). When the height of the pedicles were analyzed using fluoroscopy in anteroposterior and lateral projections no important variations were found; the distance was between 22-38 mm (Table II).

Vertebral Body: On lateral projection of the vertebral body by fluoroscopy, a height between $46-80 \mathrm{~mm}$ and an anteroposterior diameter between 63-89 mm was observed.

Difference between males and females: By CT and fluoroscopy, the values for lengths and widths are slightly higher in males than in females, but do not reveal any significant difference $(\mathrm{p}<0.05)$.

Table I. Measures of vertebral elements by computerized tomography (CT). The average and standard deviation are shown.

\begin{tabular}{llllllllllll}
\multicolumn{2}{r}{ Vertebral element } & \multicolumn{2}{c}{ L1 } & \multicolumn{2}{c}{ L2 } & \multicolumn{2}{c}{ L3 } & \multicolumn{2}{c}{ L4 } \\
Pedicles & Width & 7.81 & \pm 1.30 & 8.26 & \pm 1.42 & 9.57 & \pm 0.99 & 10.79 & \pm 0.59 & 14.36 & \pm 1.85 \\
& Length & 20.92 & \pm 2.62 & 19.86 & \pm 2.93 & 17.57 & \pm 2.12 & 16.67 & \pm 2.13 & 17.23 & \pm 1.35 \\
\multirow{3}{*}{ Body } & Anteroposterior & 32.41 & \pm 4.87 & 30.58 & \pm 2.09 & 32.07 & \pm 1.86 & 33.19 & \pm 2.59 & 37.28 & \pm 5.04 \\
& Transverse & 40.61 & \pm 3.82 & 40.16 & \pm 2.88 & 41.28 & \pm 2.21 & 44.31 & \pm 2.07 & 51.46 & \pm 6.44 \\
\multirow{3}{*}{ Spinal Canal } & Transverse & 22.46 & \pm 1.35 & 22.80 & \pm 2.14 & 23.98 & \pm 2.09 & 26.38 & \pm 2.43 & 29.78 & \pm 3.50 \\
Vector 1 & & 75.61 & \pm 7.47 & 81.67 & \pm 9.14 & 87.07 & \pm 9.76 & 89.53 & \pm 11.5 & 89.76 & \pm 13.3 \\
\hline
\end{tabular}

Table II. Measures of the vertebral elements by fluoroscopy. The average and standard deviation are shown.

\begin{tabular}{llllllllllll}
\multicolumn{1}{c}{ Vertebral element } & \multicolumn{2}{c}{ L1 } & \multicolumn{2}{c}{ L2 } & \multicolumn{2}{c}{ L3 } & \multicolumn{2}{c}{ L4 } & \multicolumn{2}{c}{ L5 } \\
Pedicles & Width & 22.28 & \pm 2.87 & 22.39 & \pm 2.64 & 24.5 & \pm 1.89 & 24.72 & \pm 2.19 & 25.56 & \pm 2.12 \\
& Height & 30.06 & \pm 3.06 & 30.44 & \pm 2.33 & 30.50 & \pm 2.66 & 29.00 & \pm 2.45 & 28.44 & \pm 2.41 \\
& Length & 40.88 & \pm 3.98 & 37.11 & \pm 4.53 & 36.6 & \pm 4.15 & 37.00 & \pm 3.9 & 37.00 & \pm 3.42 \\
\multirow{3}{*}{ Body } & Height & 57.22 & \pm 2.86 & 59.66 & \pm 9.11 & 58.22 & \pm 5.47 & 57.11 & \pm 4.37 & 59.88 & \pm 4.40 \\
& Anteroposterior & 78.77 & \pm 4.29 & 76.44 & \pm 7.51 & 79.11 & \pm 6.58 & 76.00 & \pm 7.34 & 78.55 & \pm 5.65 \\
\hline
\end{tabular}




\section{DISCUSSION}

A detailed knowledge of pedicle size and dimensions is crucial when using the pedicle to gain purchase of the vertebrae. Screw sizes must take pedicle dimensions into consideration. A valid assessment of the safty of pedicle screw insertion into small pedicles of upper lumbar spine requires $\mathrm{CT}$ imaging.

From de present study, one may assume that in a mexican population the mean narrower pedicular width $(7.81 \mathrm{~mm})$ was at L1-L2 levels. The dimensions (widths) of the $\mathrm{L} 1$ and $\mathrm{L} 2$ pedicles mesaured by $\mathrm{CT}$ are enough to insert pedicles screws. Use of a 5.5 to 6.5 screw should be safer in mexican population. Today, its posible insert subaxial cervical pedicles screws in pedicles smaller than we found in our study. A lumbar pedicle with a diameter of $7.81 \mathrm{~mm}$ will easily accommodate a $4.5 \mathrm{~mm}$ screw, especially if the pediculation is performed with a Jamshidi-cannula followed by guide-wire insertion and subsequent insertion of a cannulated screw.

Comparing our results of the pedicle width with other studies, there were differences with the reports of Mitra et al. in indians, Kim et al. in koreans and Olsewski et al. in americans. The pedicular width were wider in Indians, Korenas, and amercians than in mexicans. There some important differences in L1, L2, L5 between races, but in
L3 and L4 there is no such wide variation. This suggests that variations occur more often in transitional vertebra (upper and lower). However, we found some similarity in the report of Christodoulou et al. in Greeks \& Hou et al. (1993) in chinese population.

Several reports compare the dimension of pedicle between males and females. Olsewski et al., Christodoulou et al., Zhu et al. (2008) found differences between men and women. Ebraheim et al. (1996) did not find significant statistical differences in pedicle dimensions between male and female, just as our study did.

The locations and distances form skin to pedicle and vertebral body are important for percutaneus surgical procedures. Vector 1 contributes to define workspace for percutaneus procedures because shows the distance between skin and vertebral body througt pedicle.

CT scanning evaluation is the gold standar in determining the feasibility of pedicle screw insertion, and fluroscopy is used only to obtain the proper entry points and angulations for screw insertion intraopratively. The magnification observed in pedicle size by fluroscopy is not important for the choice of the appropriate implant.

URRUTIA, V. E.; ELIOZONDO, O. R. E.; DE LA GARZA, C. O. \& GUZMÁN, L. S. Morfometría del cuerpo vertebral y pedículo en una población mexicana mediante TC y fluoroscopia. Int. J. Morphol., 27(4):1299-1303, 2009.

RESUMEN: Es necesario tener un conocimiento anatómico preciso de la morfología de los pedículos en la region lumbar para la colocación segura de tornillos intrapediculares. No existen reportes de la morfometría de los pedículos lumbares en la población Mexicana. Se desarrolló un estudio descriptivo, observacional y transversal en 60 cadaveres en el laboratorio del Departamento de Anatomía Humana de la Facultad de Medicina. El objetivo del estudio fue determinr las características morfométricas de los pedículos de la region lumbar en una muestra de población Mexicana. Se evaluaron las regiones lumbares (L1-L5) de un total de 60 cadaveres por fluroscopía y TC en un rango de edad entre 40 y 78 años. Cada pedículo fue medido en los planos axial, sagital y coronal. La evaluacion por TC muestra un aumento progresivo y gradual de la anchura de los pedículos de L1 (7,81 $\pm 1,30 \mathrm{~mm})$ a L5 (14,36 \14,36 mm). También se observó una disminución gradul de la longitud del pedículo de L1 (14,36 $\pm 14,36 \mathrm{~mm})$ a L5 (17,23 11,35 mm). Al realizar las mediciones por fluroscopia se observaron las mismas condiciones, pero los valores fueron proporcionalmente mayores que los obtenidos por TC. La anchura y longitud pedicular fueron ligeramente mayores en hombres que en mujeres, pero no revelan significancia estadística $(\mathrm{p}<0,05)$. Los datos obtenidos del estudio indican que los tornillos intrapediculares $(5,5-6,5 \mathrm{~mm})$ pueden ser utilizados en la region lumbar.

PALABRAS CLAVE: Pediculos; Cuerpo vertebral; Morfometría; Tornillos intrapediculares; Cirugía de fusión lumbar.

\section{REFERENCES}

Christodolou, A. G.; Apostolou, T.; Ploumis, A.; Terzidis, I.; Hantzokos, I. \& Pournaras, J. Pedicle dimensions of the thoracic and lumbar vertebrae in the Greek population. Clin. Anat., 18:404-8, 2005.
Ebraheim, N. A.; Rollins, J. R.; Xu, R. \& Yesting, R. A. Projection of the lumbar pedicle and its morphometric analysis. Spine, 21(11):1296-300, 1996. 
URRUTIA, V. E.; ELIOZONDO, O. R. E.; DE LA GARZA, C. O. \& GUZMÁN, L. S. Morphometry of pedicle and vertebral body in a Mexican population by CT and Fluroscopy. Int. J. Morphol., 27(4):1299-1303, 2009.

Errico, T. J.; Gatchel, R. J.; Schofferman, J.; Benzel, E. C.; Faciszewski, T.; Eskay-Auerbach, M. \& Wang, J. C. A fair and balanced view of spine fusion surgery. Spine, 4(5):S129-38, 2004.

Gelalis, I. D. \& Kang, J. D. Thoracic and lumbar fusions for degenerative disorders. Rationale for selecting the appropriate fusion techniques. Orthop. Clin. North Am., 29(4):830-41, 1998.

Hou, S.; Hu, R. \& Shi, Y. Pedicle morphology of the lower thoracic and lumbar spine in a Chinese population. Spine, 18:1850-5, 1993.

Humphreys, S. C.; Hodges, S. D.; Patwardhan, A. G.; Eck, J. C.; Murphy, R. B. \& Covington, L. A. Comparison of posterior and transforaminal approaches to lumbar interbody fusion. Spine, 26(5):567-71, 2001.

Kim, N. H.; Lee, H. M.; Chung, I. H.; Kim, H. J. \& Kim, S. J. Morphometric study of pedicles of thoracic and lumbar vertebrae in Koreans. Spine, 19(12):1390-4, 1994.

Khoo, L. T.; Palmer, S.; Laich, D. T. \& Fessler, R. G. Minimally invasive percutaneous posterior lumbar interbody fusion. Neurosurgery, 51(5):S166-1, 2002.

Liau, K. M.; Yusof, M. I.; Abdullah, M. S.; Abdullah, S. \& Yusof, A. H. Computed tomographic morphometry of thoracic pedicles: safty margin of transpedicular screw fixation in Malaysian malay population. Spine, 15(31):E45-50, 2006.

Mitra, S. R.; Datir, S. P. \& Jadhav, S. O. Morphometric study of the lumbar pedicle in the indian population as related to pedicular screw fixation. Spine, 27:453-9, 2002.

Nojiri, K.; Matsumoto, M.; Chiba, K.; Toyama, Y. \& Momoshima, S. Comparative assessment of pedicle morphology of the lumbar spine in various degenerative disease. Surg. Radiol. Anat., 27(4):317-21, 2005.

Olsewski, J. M.; Simmons, E. H.; Kallen, F. C., Mendel, F. C.; Severin, C. M. \& Berens, D. L. Morphometry of the lumbar spine: anatomical perspectives related to transpedicular fixation. J. Bone Joint Surg. Am., 72:5419, 1990.

Zhu, R. F.; Yang, H. L.; Hu, X. Y.; He, X. S.; Tang, T. S.; Liang, C. \& Xigong, L. CT evaluation of cervical pedicle in a chinese population for surgical application of transpedicular screw placement. Surg. Radiol. Anat., 30(5):389-96, 2008.
Correspondence to:

Rodrigo E. Elizondo Omaña, MD, PhD

Departmento de Anatomía Humana

Facultad de Medicina

Universidad Autónoma de Nuevo León

Ave. Madero y Dr. Aguirre Pequeño s/n. Col.

Mitras Centro. C.P. 64460

Monterrey, N.L.

MEXICO

Email: rod_omana@yahoo.com

Received: 21-05-2009

Accepted: 07-07-2009 
